\title{
Measuring Inclinations and Attitudes of University Teachers towards Sports Activities
}

\author{
Shaimaa Abed Mutar Al-Tamimi \\ College of Physical Education, Department of practical sciences, University of Al-Mustansiriyah, Baghdad 00964, Iraq
}

\begin{abstract}
The researcher wants to know the inclinations of the teachers in Al-Mustansiriyah University into participation in sports activities and the obstacles. The aims are to build measure of trends and tendencies toward university teachers about exercise and sporting activities and identify the reasons that prevent teachers from exercise. This measure contained on 25 open questions directed by the researcher toward the university teachers, and the distribution of the questions was on three areas: cognitive domain, behavioral domain and emotional domain. These areas have a relationship between tendencies and attitudes of teachers towards sports activities, in addition to the knowledge of the problems and obstacles that prevent this group from participating in sports activities. There is a lack of correlation between the desire to practice physical activity and the presence of a sports hall at the university in terms of statistics. The difficulties in the practice of sports activities, including economic, social and other factors, insecurity and instability exist. There is a good correlation between the previous practice of physical activity and the current desire to practice in terms of statistical activities.
\end{abstract}

Key words: Trends, tendencies, sport activities, method.

\section{Introduction}

Inclinations play a major role in organizing and directing the behavior of the individual and support him to achieve his goal. It is the most important factor that contributes to the formation of an individual's personality. The aim is to prepare the individual and make it able to consistently tender, in addition to the acquisition of public health, development of physical, psychological traits and social development [1]. The trend has been defined as "a case of conscience” [2]. As Ahmed knew inclination is the sum total of the personal qualities that indicate a certain professional success [3]. While the attitudes defined as acquired sentimental preparations which is constant relatively determines the individual's sense and behavior about certain subjects [4]. It is an individual's position towards one of the values or standards prevailing in the environment [5]. So the importance of the research is in the contribution of university teachers in the sports activities, sporting events and recreational

Corresponding author: Shaimaa Abed Mutar Al-Tamimi, Ph.D., assistant professor, research fields: physic psychology and practical research. E-mail: dr.shaimaa77@ymail.com. activities organized by the director of physical education within the university, with the participation of many sports teams. These actions activated the circulation of the blood, fitness, forcing teachers to do their jobs very actively. The goal of research is to identify the inclinations and trends of teachers towards sports activities, in addition to knowledge of the problems and obstacles that prevent this group from participating in sports activities at the university and develop appropriate solutions to overcome these obstacles.

The researcher adopted the survey method in collecting data and facts for a certain position, and this method does not focus on characters of individuals, but producing a general statistics [6].

Researcher relied on a sample of university professors of Al-Mustansiriyah University. This sample was selected at random, meaning that all members of the research community have the equal and independent chance to enter the sample and everyone is in the same probability of choice (Table 1). 
Table 1 Distribution of sample.

\begin{tabular}{lllll}
\hline$n$ & Colleges & \multicolumn{2}{l}{ Certificate } & Total \\
\cline { 2 - 5 } & & Doctorate & Master & 9 \\
\hline 1 & Arts & 5 & 4 & 9 \\
3 & Education & 5 & 4 & 9 \\
4 & Science & 5 & 4 & 8 \\
5 & Management and economics & 4 & 4 & 8 \\
6 & Medical & 4 & 4 & 8 \\
7 & Engineering & 4 & 4 & 8 \\
8 & Political science & 4 & 4 & 8 \\
9 & Teachers & 4 & 4 & 8 \\
\hline Total & Law & 4 & 4 & \multicolumn{2}{c}{75} \\
\hline
\end{tabular}

In order to achieve the objectives of the research, the researcher build a scale to measure tendencies and trends for teachers of the university towards sports activities (Table A1), containing 25 open questions with distributions in three areas (cognitive domain, behavioral domain and emotional domain), related to trends and attitudes of teachers towards sports activities, in addition to the awareness of the problems and obstacles that prevent this group from participating in sports activities. The scale was presented on a group of experts in the field of psychology for the purpose of judging the validity of the measure developed for it [7]. The suitability of the measure was $80 \%$, and this guide veracity content as it was calculated reliability coefficient by re-applying the test, across calculating the correlation coefficient (The Pearson Law) between the scores of the first application and the second, to see the stability which is form of the correlation coefficient between the results of the test in two consecutive processes [8].

For recognizing the objectivity of the measurement, there was a questionnaire divided on a sample of the research. The answering of the questionnaire was very clear and without any interpretation. This leading us to conclude that all the paragraphs of the measurement which was putting by experts in psychology have got on the high objectivity. Scale of (tendencies and trends) was applied towards sports activities at the university professors. In Sunday day on 15/4/2012, a sample application amounted to 75 of a campaign professors doctoral and master's certificate has included.

In order to achieve the goal of the research, researcher used statistical methods: (1) correlation coefficient (The Pearson Law) [9]; (2) the percentage law [10]; (3) law relationship to find a consensus after determining the number of iterations in every cell of the four cells, and have been calculated using the correlation coefficient following law [11].

In the light of the research problem and purpose, the researcher presented the results of research and analysis in order to verify the correctness and conformity with the objective of this research, and for the considered view the results in tabular form.

Data from Table 2 indicate the existence of a correlation counterproductive, as it amounted correlation (19\%) between the desire to exercise activity and the presence of a sports hall in the university through a number of iterations of a sample search, which included questions (third and sixth) as distributed on four boxes, each box contains a number of iterations for the answer (yes) or (no).

Table 3 indicates that the total sample is 75 . It has been found that 13 of those who do not have any difficulties in exercising sports activities inside the university, while the number who say that there are difficulties preventing the exercise of the sports activity is 62 , and the percentage is $82 / 67 \%$. Those who 
Table 2 Correlation between the desire to exercise activity and the presence of a sports hall.

\begin{tabular}{lllll}
\hline & The third question & Sixth question & Total & Correlation \\
\hline Yes & A 40 & B 13 & 53 & \\
No & C 17 & D 5 & 22 & $19 \%$ \\
Total & 57 & 18 & 75 & \\
\hline
\end{tabular}

Table 3 Correlation between exercising for sports activities, habits, traditions, social and other factors.

\begin{tabular}{lllll}
\hline Total sample size & Sample size & Customs \& Traditions & Standard of living & Other factors \\
\hline 75 & 62 & 32 & 10 & 20 \\
Percentage & $82 / 67 \%$ & $51 / 61 \%$ & $12 / 16 \%$ & $36 / 25 \%$ \\
\hline
\end{tabular}

Table 4 Correlation between exercising for sports activities and former desire to current activity.

\begin{tabular}{lllll}
\hline & First question & Third question & Total & Correlation \\
\hline Yes & A 52 & B 6 & 58 & \\
No & C 5 & D 12 & 17 & $59 \%$ \\
Total & 57 & 18 & 75 & \\
\hline
\end{tabular}

have confirmed that there are social factors inhibiting participation was the percentage equal to 51/61\%, while the percentage who say that there are economic factors is $12 / 16 \%$, those who identified that there are other factors were accounted for 36/25\%.

Data from Table 4 indicate the existence of a correlation between the practice of physical activity and former desire to current activity, through a number of iterations, which included questions (I and III) as distributed over the four boxes, each box containing a number of iterations for answer by (yes) or (no). Using the law of compatibility, it was found that the degree of correlation equal to (59\%), which is acceptable.

\section{Results and Discussions}

The results of Table 2 indicate the lack of correlation between the desire to practice physical activity and the presence of a sports hall in the university which is a result of negative belief researcher. It is expected that there will be a positive relationship, but the reality is that no specific role for halls sports facilities exist within the university. On the other hand, it has been found that the desire to engage in activity is the foundation that leads to participation and sports activities within the halls.

Also, the social factors were one of the difficulties that have prevented the teachers from the exercise. Table 3 shows that we got the proportion (51/61\%), and the social factors are limited in customs, social traditions, the weakness of cultural awareness of the community towards the important of the sports activities in the building respects human health, physical, social and others.

The economic factor was the factor that got the ratio (16/12\%), while emerged as other factors that inhibit the practice of sports activity by the teachers of the university as it accounted for (25/32\%). These factors are limited in terms of health, old age, lack of time sufficient in addition to the circumstances of the country from wars and economic blockade, occupation, terrorism, the lack of security and stability, all these led to a lack of sports activities by the teachers of the university.

As Table 4 shows the correlation between the previous practice of sport and the desire to current practice of physical activity through the availability of appropriate conditions for this activity, this result is realistic and logical from the standpoint of the researcher, as most practitioners of sports activities of the school. The university and different age groups are a large proportion of who practiced sport in one way or another, because the practice of sports activity in which the effectiveness of certain previously lead to a 
continuation of the fun through participation. This natural reflection to see kinetic energy when human terms that any defect in the organs of the body affects the character and ability to production, but it becomes a hindrance to achieve his or her duties in life.

There are many factors that prepared by specialists sources of trends which consists social, economic conditions, political and ideology, which are in line with the evolution crossed by the community, interactive process, the different social attitudes which are important for the individual, the community and the impact of the family stage as well as cultural factors and, influences and the process of unification with some of the characters and models social which constitute an important role in the acquisition of some of the trends in individuals [12].

The most important conclusions reached by search results:

(1) The lack of correlation between the desire to practice physical activity and the presence of a sports hall at the university in terms of statistics;

(2) The existence of difficulties in the practice of sports activities, including economic, social and other factors, insecurity and instability;

(3) There is a good correlation between the previous practice of physical activity and the current desire to practice in terms of statistical activities.

Through what could be reached from the results using statistical means and within the research, sample and procedures used where possible to reach the following:

(1) To emphasize the importance of sports activities because of its many benefits, including health, psychological and social development;

(2) Get rid of the diseases of modern civilization by owning physical fitness, which is one of the necessary supplies that meet the safety body and efficiency in everyday life;
(3) Work to build bridges of dialogue between teachers and sports coaches at the university to create a common ground with them through the exchange of opinions and remove the obstacles that prevent the exercise of the sport;

(4) Spreading awareness through various media to highlight the role of sport in human progress, builds, and organizes their daily lives;

(5) To organize a series of courses within the fitness gyms in universities and to encourage university teachers to participate in.

\section{References}

[1] Joan, M. M. 1979. Leisure Activities for the Mature Adult. Burgess, Bunny Company for publishing ,USA.

[2] Osama, K. R. 2000. Physics Psychological. Cairo: Dar Al-Fiker Al-Arabi Company for Publishing, 73.

[3] Ahmed, S. Z. 1961. Educational Psychology. Cairo, Egypt: Arab Renaissance Library, 23.

[4] Rajeh, A. E. 1977. The Origins of Psychology. Cairo: Knowledge House, 123.

[5] Moukhtar, H. 1982. Principles of the Social Psychology. Jeddah, KSA: Dar Al-Bayan Al-Arabi Company for Publishing, 245.

[6] Osama, K. R. 1997. Sports Psychology Concepts \& Applications. Cairo: Dar Al-Fikr Al-Arabi Company for Publishing, 67.

[7] Ahmed, B. 1978. The Origins of Scientific Research and Curricula. Kuwait: Publications Series, Street Mahd Al-Salem Company for Publishing, 279.

[8] Abdul, R. M. A. 1974. Experimental Measurement in Psychology and Education. Beirut: Dar Al-Trbiyah Al-Arabia Company for Publishing, 58.

[9] Fouad, A. H., and Mr. Al-Issawi. 1996. Mental Calendar. Cairo: Anglo-Egyptian Company for Publishing, 95.

[10] Abdul, R. A. 1978. Principles of Descriptive Statistics. The First Part. Jordan: Al-Akssa Library, 232.

[11] Wadih, Y., and Hassan, M. A. 1992. Statistical Applications and Uses of Computers in Physical Education Research. Mosul: Library for Printing and Publishing, 2114.

[12] Zahran, Hamed Abdulsalam.1980. Guidance and Counseling. Second Type. Cairo: Aalm Al-Koutub Company for Publishing, 147. 


\section{Appendix A}

Table A1 Orientation scale trends in final format

\begin{tabular}{ll}
\hline N & Paragraph \\
\hline 1 & Do you previously practiced sports activities. \\
& Is nonexistence of sports practice return to the habits and traditions imposed on you or the standard of living or \\
2 & other factors may be psychological. \\
3 & Do you want to practice sports activities within the university now? \\
4 & Do you think that sports activities running on your spare time works? \\
5 & Are there any other conditions shift between you and sports activities. \\
6 & Is there a sports hall inside the university or college? \\
7 & Is there a sports hall or gym in your area? \\
8 & Are there sports programs good or courses within hall or club that ocean going. \\
9 & Is lack of exercise due to the shame of practice late due to age? \\
10 & Is lack of exercise due to the lack of efficient coach? \\
11 & Are the type of activity you want to practice is a social. \\
12 & Are your family members are encouraged to practice sports activities. \\
13 & Would you like numbers or recreational sports program share it with others. \\
14 & Have you visited the sports hall inside the university or college? \\
15 & Does the Directorate of sports activity invite you to participate in sports activities being undertaken in any occasion? \\
16 & Do you have a role in supporting sports activities inside and outside the university? \\
17 & Are sports activities providing service to you and the community? \\
18 & Are there factors working to attract university professors to exercise within the university. \\
19 & Can you support sports activities within the scope of your business within the university? \\
20 & Do you want to practice sports activities in the early hours of constantly? \\
21 & Is lack of exercise due to the material is not connected to the good form of staff training. \\
22 & Is lack of exercise due to the presence of disease or physical impairments? \\
23 & Is lack of exercise due to the lack of security and stability in the country? \\
24 & Is lack of exercise due to lack of exercise a family member for the sport? \\
25 & Is lack of exercise due to the lack of physical ability? \\
\hline
\end{tabular}

